Original Paper

\title{
Workshop Teknik-Teknik Pemetaan Mutu Pendidikan di Satuan Pendidikan Bagi Guru-Guru di SMA Muhammadiyah Mataram
}

\author{
Sudirman Wilian ${ }^{1}$, Wildan$^{1}$, Nyoman Sridana ${ }^{1}$, Dadi Setiadi ${ }^{*}$ \\ ${ }^{1}$ Program Studi Magister Administrasi Pendidikan, Pascasarjana, Universitas Mataram, Indonesia
}

DOI: $10.29303 /$ jpmpi.v2i2.371

Sitasi: Wilian, S., Wildan, Sridana, N., Setiadi, D. (2019). Workshop Teknik-Teknik Pemetaan Mutu Pendidikan di Satuan Pendidikan Bagi Guru-Guru di SMA Muhammadiyah Mataram. Jurnal Pengabdian Magister Pendidikan IPA (JPMPI). (2) 2. pp. 122-126

*Corresponding Author: Dadi Setiadi, Program Studi Magister

Administrasi Pendidikan, Pascasarjana, Universitas Mataram, Indonesia;

Email:

setiadi_dadi@unram.ac.id
Abstrak: Mutu pendidikan SMA swasta di Kota Mataram masih perlu ditingkatkan agar bisa memenuhi stándar nasional pendidikan salah satunya adalah SMA Muhammadiyah Mataram. Sesuai dengan hasil studi pendahuluan bahwa para guru belum memahami dan melaksanakan bagaimana memetakan mutu sekolah dan menyusun program untuk bisa menjamin mutu di SMA Muhammadiyah Mataram. Selain itu juga warga sekolah tersebut belum melaksanakan bagaimana memetakan mutu sebagai dasar untuk pengembangan program mutu sekolah. Tujuan dari kegiatan pengabdian kepada masyarakat adalah untuk memberikan pemahman kepada para guru secara komprehensfi terkait dengan bagaimana memetakan mutu sekolah; meniterpretasi hasil pemetaan mutu, menyusun program-progam mutu yang secara keseluruhan mengarah pada peningkatan mutu sekolah. Metode yang digunakan dalam pengabdian kepada masyarakat ini adalah dalam bentuk pelatihan atau workshop yang lebih berbasis pada praktek langsung menyusun instrumen pemetaan mutu, melaksanakan pemetaan mutu, menginterpretasi hasil dan menyusun tindak lanjut dari hasil tersebut berupa program mutu yang bisa menjamin peningkatn mutu di sekolah secara keseluruhan. Data hasil pengabdian dikumpulkan melalui asesmen pengetahuan dan keterampilan mengenai pemetaan mutu dan dianalisis secara deskriptif kualitatif. Hasil kegiatan menunjukan bahwa para peserta memiliki pemahaman komprehensif tentang standar nasional pendidikan untuk pendidikan menengah; indikator mutu untuk setiap standar nasional pendidikan, definisi konsep operasional tentang standar nasional pendidikan; dan terampil dalam mendisain instrumen-instrumen untuk pemetaan mutu, melaksanakan pengukuruan mutu pendidikan, menginterpretasikan hasil pemetaan mutu pendidikan dan menyusun program mutu sebagai tidak lanjut dari hasil pemetaan mutu di satuan pendidkan menengah.Pemahaman tersebut merupakan aspek penting yang harus dimiliki guru dalam memetakan mutu pendidikan di sekolah tersebut. Kompetensi tersebut merupakan dasar dan utama yang dibutuhkan untuk mendisain instrumen pengukuran mutu dan penyusunan program-program mutu satuan pendidikan menengah. Namun demikian para guru masih perlu pembimbingan dari tim dalam konteks implementasi pemetaan mutu di sekolah agar palaksanaan pemetaan mutu terlaksana dengan baik .Keterampilan dalam mendisain instrumen-instrumen untuk pemetaan mutu, pelaksanaan pengukuruan mutu pendidikan, menginterpretasikan hasil pemetaan mutu pendidikan dan menyusun program mutu sebagai tidak lanjut dari hasil pemetaan mutu yang dimiliki para guru yang sudah baik menunjukan bahwa guru sudah mampu mendisaian bagaimana melaksanakan pemetaan mutu satauan pendidikan menengah. Para guru peserta kegiatan pengabdian memiliki pemahaman yang baik terkait dengan pemetaan mutu dan keterampilan dalam mendisain instrumen dan tindak lanjut program mutu, sehingga para guru tersebut mampu melaksanakan pemetaan mutu secara baik di SMA Muhammadiyah Mataram sebagai dampaknya mutu proses dan hasil belajar di sekolah tersebut bisa menjadi lebih baik.

Kata Kunci : Workshop; Pemetaan Mutu Satuan Pendidikan. 


\section{Pendahuluan}

Pemetaan mutu merupakan proses terkait kegiatan pengumpulan, pengolahan, analisis data dan informasi tentang capaian pemenuhan standar nasional pendidikan dari mulai tingkat sekolah, kabupaten/kota, provinsi, hingga nasional (Sekretariat Direktorat Jenderal Pendidikan Dasar dan Menengah, 2017). Pemetaan tersebut memberikan gambaran kepada berbagai pemangku kepentingan khususnya pengelola pendidikan di tingkat sekolah tentang capaian pemenuhan standar pendidikan (Direktorat Jenderal Pendidikan Dasar dan Menegah, 2016a). Salah satu tahapan yang harus dilakukan dalam menjalankan penjaminan mutu pendidikan di sekolah baik secara internal maupun eksternal (Mentri Pendidikan dan Kebudayaan Republik Indonesia, 2016). Dari hasil pemetaan tersebut dihasilkan peta atau gambaran mutu pendidikan yang dapat dimanfaatkan oleh sekolah khususnya sebagai acuan dalam perencanaan perbaikan dan peningkatan mutu pendidikan sesuai kewenangan sekolah. Pemetaan mutu harus mengacu pada standar nasional pendidikan dengan menggunakan instrumen yang dikembangkan oleh Direktorat Jenderal Pendidikan Dasar dan Menengah (2016b). Menurut Pemerntah Republik Indonesia (2003) bahwa standar nasional pendidikan mencakup keseluruhan komponen pendidikan yang saling terkait secara terpadu untuk mencapai tujuan pendidikan nasional. Variabel pertanyaan dalam instrumen dibangun dari subindikator mutu dan diidentifikasi sumber data dan informasi yang mendukung.

Sekolah melakukan kegiatan pemetaan mutu melalui evaluasi diri sekolah (EDS) dan menyampaikan hasil evaluasi tersebut dalam bentuk data dan informasi sesuai dengan instrumen pemetaan mutu yang dikembangkan oleh Direktorat Jenderal Pendidikan Dasar dan Menengah (2017). Data dan informasi tersebut secara umum bisa memberikan gambaran terkait dengan mutu sekolah, data tersebut dikirim ke sistem informasi mutu pendidikan untuk diolah menjadi peta mutu yang memuat capaian pemenuhan terhadap standar nasional pendidikan untuk disampaikan kepada sekolah. Peta mutu dianalisis lebih lanjut sehingga dapat digunakan sebagai acuan perencanaan pendidikan oleh sekolah khsusnya dan pemerintah daerah dan pusat pada umumnya. Sehingga upaya pemenuhan mutu pendidikan di SMA Muhammadiyah bisa berjalan sinergis.
Berdasarkan studi awal di lapangan khususnya pada guru dan tenaga kependidikan SMA Muhammadiyah belum memiliki pemahaman pengetahuan dan keterampilan yang komprehensif dan sama dalam penjaminan mutu di satuan pendidikan. Sebagai langkah awal penjaminan mutu terlebih dahulu para guru dan tenaga kependidikan harus memahami standar nasional pendidikan termasuk indikator-indikatornya. Selain itu warga sekolah muhammadiyah belum memahami dengan baik bagaimana memetakan mutu pendidikan di satuan pendidikan menengah khususnya tingkat SMA termasuk interpretasi hasilnya dan tindak lanjut dari pemetaan mutu tersebut.

Berdasarkan uraian di atas, untuk menyelesaikan masalah tersebut yang hadapi oleh para guru-guru SMA Muhammadiyah Mataram, maka diajukan salah satu solusi dengan cara memberikan workshop pada guru-guru dan tenaga kependidikan SMA Muhammadiyah Mataram yang lebih berbasis pada praktek dan pembimbingan langsung dalam penyusunan instrument dan teknik pelaksanan pemetaan mutu serta tindak lanjut dari hasil pemetaan mutu tersebut, sehingga bisa meningkatkan mutu sekolah yang bersangkutan.

\section{Metode Pelaksanaan}

Tempat pelaksanaan kegiatan PPM di SMA Muhammadiyah Mataram pada semester gasal tahun akademik 2019/2020. Model pelaksanaan yang digunakan dalam pengabdian ini adalah workshop, peserta diberikan penjelasan tentang materi workshop teknik-teknik pemetaan mutu pendidikan di satuan pendidikan bagi guru-guru di SMA Muhammadiyah Mataram dalam bentuk kelompok. Populasi adalah semua guru SMA Muhammadiyah Mataram, sampel yang digunakan sebanyak 30 orang guru. Pengumpulan data dilakukan dengan mengevaluasi hasil kegiatan berupa pengetahun dan keterampilan tentang teknikteknik pemetaan mutu pendidikan di satuan pendidikan. Hasil PPM berupa data skor kuantitatif dan kualitatif kemudian dianalisis secara deskriptif kualitatif (Sugiyono, 2008a: 2008b). 


\section{Hasil dan Pembahasan}

Hasil kegiatan menunjukan bahwa para guru peserta pengabdian memiliki pemahaman komprehensif standar nasional pendidikan untuk pendidikan menengah diman pemahaman yang dimiliki guru tersebut ditunjukan hasil evaluasi pada saat pelaksanaan dan akhir kegiatan. Pemahaman yang baik tersebut merupakan pemahaman yang melengkapi pemikiran guru yang selama ini hanya fokus pada yang menjadi kewajibannya saja seperti standar isi, proses dan evaluasi. Oleh karena itu kegiatan pengabdian bisa memberikan wawasan kepada guru terkait dengan standar nasional pendidikan yang harus dipenuhi satauan pendidikan menengah khususnya SMA Muhammadiyah Mataram.

Pemahaman standar nasional pendidikan terkait dengan pemahaman guru tentang indikator mutu untuk setiap standar nasional pendidikan. Pemahaman indikator mutu sangat penting untuk bisa menyusun instrumen yang bisa menggambarkan sebaik apa mutu yang dimiliki satuan pendidikan atau sejauh mana mutu yang dicapai satuan pendidikan tersebut dibandingkan dengan standar nasional pendidikan. Sehingga indikator indikator mutu tersesebut sangat perlu dimiliki guru yang telah ditunjukan oleh peserta pada hasil pengukuran akhir kegiatan pengabdian.

Hasil menunjukan bahwa para guru memahami definisi konsep dan operasional tentang standar nasional pendidikan. Pemahaman tersebut sangat penting untuk mendisaian atau merumuskan indikator-indikator untuk pengukuran tingkat ketercapaian standar nasional pendidikan. Pemahaman definisi tersebut sebagai awal penyusunan indikator dan instrumen untuk pengukuran mutu tersebut di satuan pendidikan menengah khususnya di SMA Muhammadiyah Mataram. Pemahaman tersebut dapat mendukung untuk penyusunan instrumen yang memiliki validitas dan reliabilitas instrumen sehingga bisa dihasilkan instrumen yang baik dan memenuhi syarat dari aspek akademik pengukuruan mutu pendidikan.

Keterampilan guru peserta pengabdian menunjukan sudah baik dalam mendisain instrumen-instrumen untuk pemetaan mutu satuan pendidikan menengah. Keterampilan tersebut sangat penting untuk pemetaan mutu satuan pendidikan dengan alasan baiknya kualitas instrumen pemetaan mutu akan bisa menunjukan mutu yang sebenarnya tetapi jika sebaliknya maka tidak akan bisa menggambarkan mutu sebenarnya dari satuan pendidikan.

Guru telah memiliki keterampilan yang cukup baik dalam teknik-teknik pelaksanaan pengukuruan mutu pendidikan di satuan pendidikan. Keterampilan tersebut sangat menentukan tingkat kualitas dari pelaksanaan pemetaan mutu satuan pendidikan sehingga bisa menggamabrkan mutu yang sesuangguhnya. Tetapi dalam hal pelaksanaan sebenarnya guru tersebut masih perlu diarahkan agar pelaksannaannya bisa lebih baik sesuai dengan prosedur yang berlaku dan agar guru tersebut memiliki pengalaman yang baik dalam pelaksanaan pengukuran mutu sataun pendidikan.

Guru telah menunjukan keterampilan yang baik dalam menginterpretasikan hasil pemetaan mutu pendidikan di satuan pendidikan menengah, dimana keterampilan tersebut sangat penting karena akan terkait dengan kegiatan berikutnya yaitu penyusunan progra-program mutu. Keterampilan interpretasi terkait dengan pemahaman secara komprehensif tenatng pemetaan dan pengembangan mutu sehingga masih perlu ditingkatkanpemahaman secara maksimal tentang mutu nasional pendidikan dan perlu banyak latihan menginterpretasi terkait dengan data hasil pemetaan mutu pendidikan.

Keterampilan guru sudah baik dalam menyusun program mutu termasuk pembiayaan (Hidayah, dkk, 2014) sebagai tidak lanjut dari hasil pemetaan mutu di sekolah. Para guru tersebut sudah memahami bagaiman menysusun program-program mutu yang didasarkan pada kualitas mutu yang dicapai termasuk mengintergasikan manajemen berbasis sekolah (Mahsun, 2013) sehingga programprogram mutu tersebut mendukung pencapaian mutu yang lebih baik dari yang telah dicapai. Selain itu program mutu harus rasioanl sesuai dengan kondisi sumber daya sehingga bisa dicapai secara berkelanjutan bisa mencapai atsandar basionala atau lebih yang kan berdampak pada semakin baiknya input yang diterima oleh satuan pendidikan terkait.

Pemahaman yang baik dari guru tentang standar nasional pendidikan untuk pendidikan menengah menunjukan bahwa guru-guru tersebut memahami standar pendidikan secara terpadu dan saling terkait sehingga tidak bisa mencapai standar nasional jika belum memenuhi standar nasional secara keselurahan. Pemahaman tersebut sangat perlu dimiliki oleh semua tenaga pendidik karena banya pendidik hanya paham yang terkait dengan standar isi, proses dan evaluasi termasuk standar 
kompetensi tenaga pendidik dalam usha mencapai prestasi (Rharjo, 2014). Dengan demikian para peserta tersbut harus memiliki pemhaman dan konsep yang kuat bahwa stndar pendidikan tidak hanya terkait dengan tugas utama guru saja tetapi terkait dengan yang lain dan akhirnya adalah mencapai standar kompetensi lulusan mencakup aspet pengetahaun, keterampilan dan sikap.

Pemahaman guru yang sudah cukup baik tentang indikator mutu untuk setiap standar nasional pendidikan artinya bahwa guru sudah memahami bahwa standar mutu pendidikan adalah gambaran tingkat keteracapaian indikator dari mutu pendidikan secara nasional. Namun demikian guru juga harus memahami secara komprehensif bagimana mencapai indikator tersebut secara menyeluruh sehingga perlu disusun bersama dengan semua warga sekolah terkait dengan penyusunan dan pencapaian indikator, Namun demikian para guru masih perlu arahan dan bimbingan dari pihan tim pengabdian agar sesuai dengan prosedur yang berlaku.

Pemahaman guru yang baik terkait definisi konsep dan operasional tentang standar nasional pendidikan menunjukan bahawa guru akan berpluang bisa menysusun intstrumen asesment mutu. Karena dengan pemahaman tertsebut guru akan bisa menjabarkan sejumlah indikator yang manjdi dasar penyusunan instrumen pemetaan mutu satauan pendidikan menengah. Pemahaman tersebut masih perlu diperdalam dan diperluas agar guru dalam penjabaran indikator sesuai dengan standar mutu yang hendak dicapai. Selain itu perlu memiliki wawasan yang lebih luas karena definsi operasional sangat tergantung dari tagihan luaran dari hasil pendidikan menengah khususya.

Keterampilan guru yang sudah cukup baik dalam mendisain instrumen-instrumen untuk pemetaan mutu satuan pendidkan menengah menunjukan bahwa guru sudah memhami tahapan sebelumnya dalam pelaksanaan pemetaan mutu satauan pendidikan. Namun demikian instrumen yang dibuat peserta pengabdian perlu dicek dan direvisi jika terjadi kekurangan dengan alasan bahwa para guru tersebut belum memiliki pengalaman yang cukup baik terkait dengan pelakanaan pemetaan mutu satuan pendidikan. Instrumen yang digunakan untuk menggambarkan mutu harus memiliki validitas isi yang memenuhi persyaratan sehingga perlu kerjasama tim pengabdian dengan guru pelaksanan pemetaan mutu di sekolah.
Keterampilan guru yang sudah baik dalam melaksanakan pengukuruan mutu pendidikan di satuan pendidikanmenunjukan sudah bisa melaksanankan pengkuruan mutu sesuai dengan porsedur standar, sehingga akan bisa menunjukan bahawa proses sudah baik kan menghasilkan hasil yang sesuai dengan kenyataan mutu. Tetapi pelaksanaan tersebut akan sulit dialksanankan tanpa kerjasam banyak pihak baiak warga sekolahmaupun komite dan stake hlder lain. Oleh akrena itu ketermapilan tersebut perlu dilatih dan di arahalan oleh pihat]k tim pengabdian masyarakat sehingga prosesnya kaan lebih berkualitas sesuai dengan prosedur baku.

Keterampilan guru dalam menginterpretasikan hasil pemetaan mutu pendidikan di satuan pendidikan menengah menunjukan bahwa para peserta tersebut sudah memahami terkait dengan muatan mutu yang harus dipenuhi satuan pendidikan, kemampuan tersebut harus dikembangkan terus agar bisa mengembangkan progrtam pada langkah berikutnya. Baik tidakanya kemampuan menginterpretasi hasil akan mennetukan penyelesaian masalah mutu di satuan pendidikan sehingga dalam menginterpretasi hasil mutu perlu didiskusikan dengan sejumlah tenaga pendidik, stakeholder lain dan kependidikan bahkan jika memungkinkan dengan tenaga ahli di bidang pendidikan agar bisa menyeluruh dan akan mempermudah dalam penyelesaian masalah mutu melalui pengembangan program mutu pada langkah-langkah selanjutnya..

Keterampilan guru dalam menyusun program-program mutu sebagai tidak lanjut dari hasil pemetaan mutu di sekolah menunjukan bahwa guru-guru peserta tersebut sudah mampu memiliki kompetensi terkait dengan mutu dan permasalahannya serta strategi mengatasinya melalui program program mutu termasuk proses pembelajaran (Puspita 2017) yang disusun di sekolahnya. Kemampuan menyusun program mutu yang dimiliki guru tersebut sebaikna tetap di kontrol oleh tim agar bisa lebih sesuai dengan permasalahan yang hadapi termasuk strategi implementasinya di sekolah terkait, sehingga bisa sesuai dengan kondisi sekolah terkait dan sumber daya yang tersedia, namun tetap secara bertahap bisa meningkatkan mutu pendidikan di sekolah tersebut.

Pemahaman dan keterampilan terkait dengan bagaimana pemetaan mutu satuan pendidikan merupakan kompetensi yang harus dimiliki oleh tanaga pendidik dan kependidikan di setiap satuan 
pendidikan/sekolah menengah. Kompetensi tersebut sangat terkait dengan pemetaan mutu, penjaminan mutu internal dan peengembangn mutu di satuan pendidikan. Dengan demikian kualitas mutu pendidikan di satuan pendidikan menengah sangat tergantung dari kemampuan warga sekolah termasuk tenaga pendidik terkait dengan mutu dan pengembangannya. Sehingga mutu pendidikan di setiap satuan pendidikan menengah selalu menunjukan peningkatan ke arah yang lebih baik dan bisa mencapai atau melebihi standar nasional pendidikan menengah (Damanik, 2015).

\section{Kesimpulan}

Berdasarkan hasil kegiatan dan pembahasan maka dapat disimpulkan bahwa: 1) Guru telah memiliki pemahaman seacara komprehensif standar nasional pendidikan untuk pendidikan menengah; 2) Guru telah memiliki pemahaman secara baik tentang indikator mutu untuk setiap standar nasional pendidikan; 3) Guru telah memiliki pemahaman secara baik definisi konsep operasional tentang standar nasional pendidikan; 4) Guru memiliki keterampilan dalam mendisain instrumen-instrumen untuk pemetaan mutu satuan pendidkan menengah; 5) Guru memiliki keterampilan dalam pengukuruan mutu pendidikan di satuan pendidikan; 6) Guru memiliki keterampilan dalam menginterpretasikan hasil pemetaan mutu pendidikan di satuan pendidikan menengah; dan 7) Guru memiliki keterampilan dalam menyusun program mutu sebagai tidak lanjut dari hasil pemetaan mutu di sekolah.

\section{Ucapan Terimakasih}

Ucapan terima kasih disampaikan kepada Bapak Rektor Universitas Mataram atas dukungan dana PPM dan guru guru SMA Muhammadiyah Mataram pertisipasi dan kerjasamanya yang sangat baik.

\section{Daftar Pustaka}

Damanik, J. 2015. Upaya dan Strategi Pemenuhan Standar Nasional Pendidikan. $J$ D $P$, Vol. 8 (3) $151-160$.
Direktorat Jenderal Pendidikan Dasar dan Menengah. 2016. Pedoman Umum Sistem Penjaminan Mutu Pendidikan Dasar dan Menengah. Jakarta: Direktorat Jenderal Pendidikan Dasar dan Menengah Kementrian Pendidikan dan Kebudayaan.

Direktorat Jenderal Pendidikan Dasar dan Menengah. 2016. Petunjuk Pelaksanaan Penjaminan Mutu Oleh Satuan Pendidikan. Jakarta: Direktorat Jenderal Pendidikan Dasar dan Menengah Kementrian Pendidikan dan Kebudayaan

Hidayah, I., Susilowati, E., dan Sukirman. 2014. Analisis Pembiayaan Pendidikan SMA dI Kota Semarang. Riptek Vol. 8 (2) 13 - 22.

Mahsun, H. 2013. Strategi Peningkatan Mutu Pendidikan Melalui Manajemen Berbasis Sekolah. Media Bina Ilmiah. Vol. 7 (6).

Menteri Pendidikan dan Kebudayaan Republik Indonesia, 2016. Peraturan Menteri Pendidikan dan Kebudayaan Republik Indonesia Nomor 28 Tahun 2016 Tentang Sistem Penjaminan Mutu Pendidikan Dasar dan Menengah. Jakarta: Kementrian Pendidikan dan Kebudayaan.

Pemerintah Republik Indonesia. 2003. Undangundang Nomor 20 Tahun 2003 tentang Sistem Pendidikan Nasional. Jakarta: Pemerintah Republik Indonesia.

Puspitasari, H. 2017. Standar Proses Pembelajaran Sebagai Sistem Penjaminan Mutu Internal di Sekolah. Muslim Heritage. Vol. 1 (2).

Raharjo, S. B. 2014. Kontribusi Delapan Standar Nasional Pendidikan Terhadap Pencapaian Prestasi Belajar. Jurnal Pendidikan dan Kebudayaan, Vol. 20 (4)

Sekretariat Direktorat Jenderal Pendidikan Dasar dan Menengah, 2017. Perangkat Instrumen Pemetaaan Mutu Pendidikan Dasar dan Menengah Tingkat Sekolah Menengah Atas. Jakarta: Sekretariat Direktorat Jenderal Pendidikan Dasar dan Menengah Kementerian Pendidikan dan Kebudayaan 